\title{
Inter- and intra-patient circadian variabilities in eight urinary modified nucleosides excretion in patients with metastatic colorectal cancer
}

\author{
Sandrine Dulong ( $\nabla$ sandrine.dulong@inserm.fr) \\ Universite Paris-Sud https://orcid.org/0000-0001-5529-0701 \\ Huang Qi \\ University of Warwick \\ Innominato Pasquale Fabio \\ University of Warwick School of Life Sciences \\ Karaboue Abdoulaye \\ INSERM \\ Bouchahda Mohamed \\ Assistance Publique - Hopitaux de Paris \\ Pruvost Alain \\ Commissariat a l'Energie Atomique et aux Energies Alternatives Centre de Saclay \\ Théodoro Frédéric \\ Commissariat a l'Energie Atomique et aux Energies Alternatives Centre de Saclay \\ Agrofoglio Luigi \\ Universite d'Orleans Bibliotheques \\ Adam René \\ Assistance Publique - Hopitaux de Paris \\ Finkenstädt Barbel \\ University of Warwick \\ Lévi Francis \\ INSERM
}

\section{Research article}

Keywords: Inter- and intra-patient circadian variabilities, in eight urinary modified nucleosides excretion in patients with metastatic colorectal cancer

Posted Date: October 31st, 2019

DOl: https://doi.org/10.21203/rs.2.16676/v1

License: (c) (i) This work is licensed under a Creative Commons Attribution 4.0 International License. Read Full License 


\section{Abstract}

Background : Modified nucleosides reflect nucleic acids turnover, and are eliminated into the urine. They can serve as noninvasive biomarkers for monitoring tumour dynamics, and treatment responses. Methods : 8 modified nucleosides were determined by LC-HRMS in urine voids collected in three linical trials recorded on NCT01693848, NCT01693861 and NCT01693835 by a total of 39 patients. The patients' circadian timing system was studied by wrist actimetry. Rhythms parameters were estimated using Hidden Markov model (HMM) for telemetric activity data and cosinor analysis for urinary nucleosides excretion.

Results : Pseudouridine, was 10-fold larger than those of 1-methylguanosine, 1-methyladenosine, or 4-acetylcytidine, and 100 fold larger than those of adenosine and cytidine. In St 1, a significant increase in the overnight urinary excretion of 1methylguanosine was associated with prolonged 4-year survival in patients with R1 resection for liver metastases. In St 2, a significant increase in one nucleoside excretion after chemotherapy was associated with that in plasma carcinoembryonic antigen 1-2 months later, and poor survival. In St3, ten fractionated urines were collected over 2-days. Circadian and/or 12-h rhythms were found in up to $48.3 \%$ of the patients for pseudouridine. Rhythm amplitudes were significantly associated with restactivity circadian parameters.

Conclusion : Urinary excretion dynamics of modified nucleosides appeared useful for tracking early responses to surgical or medical treatments, and for characterizing circadian control of cellular proliferation in colorectal cancer patients.

\section{Introduction}

Colorectal cancer is the second cause of cancer-related deaths, making it critical both to detect and treat it as early as possible in order to enhance survival and cures. Elevated circulating levels in carcinoembryonic antigen (CEA) and carbohydrate antigen CA19.9 have proven their clinical usefulness for assessing treatment responses and detecting early relapse [1]. More recently, circulating tumor cells, cell-free DNA and RNA or exosomes, have been proposed as blood biomarkers for monitoring colorectal malignancies [2]. The several nucleosides that result from DNA or RNA breakdown undergo post-transcriptional chemical modifications yielding ultrafilterable modified nucleosides that cannot be re-utilized or be degraded further, and are excreted as such into the urines. These modified nucleosides belong to the family of the ribosyl-nucleosides, twenty of which have been proposed as tumor markers for cancers of the colon or liver[3, 4], breast [5-7] or lung [8]. More specifically, the isomerisation of uridine, a nucleic acid base that composes RNA, results in pseudouridine, which is incorpored into tRNA and released in the systemic circulation then ultrafiltrated into the urine following nucleic acids breakdown, primarily including tRNA[9]. The desamination of adenosine yields inosine. The methylation of common bases that compose DNA or RNA lead to the formation of 1-methyladenosine, 1-methylinosine, 1-methylguanosine, and N2-N2-dimethylguanosine. Modified DNA base 4-acetylcytidine results from the desacetylation of cytidine. All these biochemical reactions occur at post-transcriptionnal level, and were reportedly enhanced in cancer, as a result of increased cellular metabolism and accelerated RNA turnover in tumor cells[10, 11].

The current study aimed to determine whether these modified nucleosides could serve as non-invasive and quantifiable markers of dynamic changes in tumors, after liver surgery, chemotherapy or along the 24-hours. Regarding the latter, 24-h changes have been documented for several circulating tumour biomarkers, including carcinoembryonic antigen (CEA), and CA125 [12-14], as well as for urinary excretion patterns of polyamines or myelomatous immunoglobulin [15]. While rhythms were scarcely detectable in groups of patients, striking rhythmic patterns were demonstrated in individual patients $[12,14]$. The identification of such patient-specific circadian control of cancer processes could in turn help optimize treatment timing and enhance efficacy. The circadian timing system (CTS) is a hierarchically coordinated network of molecular clocks that regulates mammalian physiology, as well as cellular metabolism, proliferation, and survival along the 24-hours [16,17]. The disruption of the rhythms that are generated by the CTS has been associated to disease processes and impaired treatment effects (for review see [18-20]). Circadian rhythms are generated at single-cell level by molecular clocks, consisting of interwoven transcriptional translational feedback loops involving some 15 known specific "clock"genes including Bmal1, Clock, Period 1 and 2, Cryptochrome 1 and 2 and Rev-erba [21, 22]. The molecular clocks are coordinated at the whole organism level by the suprachiasmatic nuclei, a hypothalamic pacemaker, which also helps circadian rhythms adjust to light-dark and other environmental 24-hour cycles through the rhythmic control of rest-activity, body temperature, feeding, as well as cortisol and melatonin secretions and 
autonomic nervous sytem activities ${ }^{1}$. Both glucocorticoids and body temperature rhythms reset molecular clocks and cellular circadian rhythms both in vitro and in vivo [23-27].

The evaluation of CTS robustness or disruption in healthy or sick humans during their daily routine has mostly involved the noninvasive recording of the rest-activity rhythm, using a wrist-worn accelerometer. In cancer patients, the relative amount of activity in bed that was below the median activity out of bed, the so called dichotomy index $1<0$, has been identified as an independent predictor of progression-free survival and overall survival among 436 patients with metastatic colorectal cancer [28, 29].

Here we determined the urinary excretions of 6 to 8 nucleosides in patients with metastatic colorectal cancer recruited in up to three studies. We assessed inter- and intra-patient changes in these potential biomarkers after partial hepatectomy Study (St) 1) or chronochemotherapy (St2), and along the 24 hours (St3). We characterized the clinical significance of such changes and linked the 24-h variations in nucleosides excretion with the rest-activity circadian rhythm.

\section{Methods}

\section{Study design}

The patients had a histological proof of metastatic colorectal cancer, a Performance Status of 0 or 1 according to the classification of the World Health Organisation and adequate biology. They had received one, two or three prior chemotherapy protocols and provided a signed informed consent for their participation. The study took place at the Department of Hepatobiliary Surgery (St1) or Oncology (St2 and 3) at Paul Brousse University Hospital (Villejuif, France). For St2 and 3, the rest activity rhythm was monitored using a wrist-worn piezoelectric accelerometer watch (Mini-Motionlogger Actigraph, Ambulatory Monitoring, Ardsley, New-York, USA) for 17 days (St2, data not reported here) or 5 days (St3). The user-defined time interval for the count of wrist accelerations was $1 \mathrm{~min}$. Each patient also completed a sleep and feeding routine during the days of recording.

St1 investigated changes in the urinary excretions of six nucleosides according to patients' characteristics before and after liver metastases resection (Figure S1a). Early morning urine voids were collected daily for 3 days before and 7 days after partial hepatectomy. Plasma carcinoembryonic antigen (CEA) and Carbohydrate antigen 19-9 (CA19-9) were determined before and 1 month after hepatectomy. The type and quality of surgical resection were classified according to standard macroscopic and microscopic assessment criteria.

St2 investigated changes in the urinary excretions of six nucleosides according to patients' characteristics before, during and after a course of chrono-chemotherapy [30] (Figure S1b). Early morning voids were collected daily for 3 days before and 14 days after the onset of a treatment course. Adverse events were rated after the chemotherapy course that was administered while on study, according to Common Terminology Criteria for Adverse Events (CTCAE) v4.0. Plasma CEA and CA19.9 were determined before and within up to 2.5 months following inclusion.

St3 investigated circadian changes in the urinary excretion of nine nucleosides according to patients' characteristics and restactivity rhythms. The device was worn continuously for 5 days, including 3 days of baseline, and 2 days during which urinary samples were self-collected (Figure S1c). The patients collected urine samples of 5-20 mL into pre-labelled sterile tubes, at 07:00 or upon awakening, then at 11:00,15:00, 19:00 and 23:00 or just prior to retiring for two consecutive days, resulting in a total of 10 samples per patient.

The survival of each patient was computed from the date of inclusion in each St to the time of death or the last time known to be alive. These data were updated in March 2019.

\section{Urinary collections and nucleosides determinations}

Nine modified nucleosides, namely pseudouridine, 1-methylguanosine, N2-N2-dimethylguanosine, 1-methyladenosine, 4acetylcytidine, 1-methylinosine, adenosine, cytidine, and 8-hydroxy-2'-deoxyguanosine were determined with mass spectrometry. The Q-Exactive, composed of the Orbitrap mass analyzer combined with a quadruple mass filter as front-end, was chosen for the

Page 3/18 
quantification of urinary nucleosides due to its sensitivity and the linearity performance of the High Resolution Mass Spectrometry (HRMS) based quantification [31]. Three of the nine nucleosides to be monitored were selected to be used as labeled internal standards for the entire quantification process (adenosine [ribose-13C5], 8-hydroxy-2'-deoxyguanosine (15N5) and 1-methyl-adenosine-D3). Due to the high concentration of most nucleosides in urine, the technique of "dilute and shoot" was chosen. A dilution of the urine sample in water by a factor of 5 was applied as a pre-treatment overcoming the major matrix effects encountered in LC/MS bioanalysis techniques. Then, a $10 \mu \mathrm{L}$ aliquot of the diluted urine was injected into the analytical system. The ultra-high pressure chromatographic (UHPLC) method was developed using a reverse phase column. The separation was performed on a column Acquity UPLC BEH Shield® $1.7 \mu \mathrm{m} 2.1 \times 100 \mathrm{~mm}$ (Waters, France). Mobile phases were distributed in a gradient mode (Dionex Ultimate 3000 system). Detection by high-resolution mass spectrometry in full scan mode was accomplished using a Q-Exactive (Orbitrap technology, ThermoFisherScientifics) after ionization in positive mode. The total analysis runtime was 7 minutes. This method was successfully validated according to the European recommendations [32].

\section{Statistical analysis}

\section{Hidden Markov Model (HMM) for Quantifying of Circadian Rhythmicity in Telemetric Activity Data}

A recently developed harmonic Hidden Markov Model (HMM) approach[33] was applied to compute numerical quantifiers associated with sleep quality and circadian rhythm in actigraphy data for St 3 patients. The HMM is a well-known statistical model which assumes that the observed time series data are a realization of a Markov process with unobserved states. In this study, the HMM approach was applied to threshold the actigraphy measurement into three states in a probabilistic way, namely inactive/rest state (IA), moderately active (MA) state and highly active (HA) state. The following circadian rhythm associated parameters derived from HMM are of particular interest[34]: 1) p1-1 (the transition probability of staying in IA); 2) median activity value at HA state, which provides an estimate of daily activity amplitude; 3 ) rest duration (integral of IA profile over the 24 hours, i.e. dark grey area a in Figure S5;4) center rest time (gravity center of IA, i.e. c in Figure S5); 5) Rhythm Index, which assumes a value of $100 \%$ for a subject with regular daily bedtimes, an IA state with a transition probability of one (case in light grey, Figure S5),, and in contrast, a value of $0 \%$ in the absence of a circadian regulation of the rest duration (case in black, Figure S5)..

We also computed the autocorrelation at 24-h (r24), a measure of the regularity of the 24-h rest-activity pattern from day to day, as well as the dichotomy index $(\mathrm{I}<0)$, defined as the percentage of activity in-bed $(\mathrm{I})$ that was less than the median activity outof-bed (0)[28, 35]. Furthermore, we also computed for each patient the dominant period using the spectrum-resampling (SR) algorithm of Costa et al.[36], as well as the acrophase and amplitude using a cosinor model.

\section{Cosinor Analysis for Quantifying of Circadian Rhythmicity in Urinary Nucleosides Excretion}

A multiple-component cosinor model [37] was applied to describe the circadian pattern of nucleosides excretion for St 3. More specifically the model contained two cosine functions with respective periods T12 $=12$-h and T24 = 24-h:

$y t=M+A 12 \cos 2 \pi t T 12+\theta 12+A 24 \cos 2 \pi t T 24+\theta 24+e t(1)$,

where $y t$ is the urinary nucleosides excretion at time $t$; $\mathrm{M}$ is the mesor (mean level); $\mathrm{A} 12, \mathrm{~A} 24$ and $\theta 12, \theta 24$ are the corresponding amplitude and acrophase for each cosine term; et is the error.

The five parameters, i.e., $\mathrm{M}, \mathrm{A} 12, \mathrm{~A} 24, \theta 12, \theta 24$ in the non-linear model (1), were estimated using the $R$ package $n / m e[38]$ To avoid over-fitting, individuals with less than seven timed nucleosides excretion samples were excluded from the cosinor analysis. We report the overall circadian amplitude A, i.e. half difference of the highest and lowest values of curve fitting ŷt, relative amplitude (\% of mesor) and the overall acrophase $\theta$, i.e. acrophase of ŷt. Nucleosides excretions were identified to have significant rhythmic 
pattern at 24-h if either amplitude (A12 or A24) was significantly different from zero ( $t$-test with $p$-value $\leq 0.1)$. Note that the liberal $0.1 \mathrm{p}$-value threshold was selected due to limited sample size, i.e. six parameters in model (1) need to be estimated by up to 10 data samples. In order to improve upon the model fit and the assumption of Gaussianity for the residuals, the log transformation was applied to the raw nucleosides excretion before the cosinor analysis. The mesor and amplitude results were transformed back to the original scale for reporting.

\section{Correlation between Circadian Parameter Estimates}

The Spearman rank correlation was computed between any pair of parameters related to rest-activity and urinary nucleosides excretion patterns. As the sample size of urinary nucleosides excretion data was limited to ten timed samples per patient, the significance threshold for rhythm detection was set to $p$-values $\leq 0.1$. Since large uncertainties could be expected for all parameter estimates related to nucleosides excretion, correlations related with nucleosides parameters were further verified by bootstrap uncertainty estimates[39]. One thousand bootstrap trials were generated via sampling the residuals in equation (1) with replacement and 1000 bootstrap nucleosides paramters were computed. The correlations were identified to be significant if the $90 \%$ quantiles of bootstrap Spearman correlation p-values $\leq 0.1$.

\section{Regression Analysis of parameter estimates versus patients' characteristics}

Multivariate regression analysis was applied to estimate the relation between main patient characteristics and response variables. The latter included the estimated parameters characterizing the rest-activity cycle, namely the dichotomy index $1<0$, the estimated probability of staying in the rest state $\mathrm{p} 1-1$, the rest duration, the Rhythm Index RI, the median value of the HA state and the autocorrelation r24; and those in the nucleosides urinary excretion, such as the mesor estimates, the relative amplitude (\% of mesor) and the number of nucleosides with significant rhythmicity pattern at 24-h. Stepwise model selection based on Akaike's information criterion[40], as implemented in the $R$ function stepAIC, was applied to obtain an appropriate model for each response variable.

\section{Results}

\section{Patients characteristics}

The three observational studies (St) were conducted in a total of 39 patients with metastatic colorectal cancer, with 16 of them participating to 2 or 3 St at various stages of their disease (Figure 1, Table 1). St 1 involved a first cohort of 10 patients whose liver metastases had responded to chemotherapy so that they could undergo partial hepatectomy with curative intent. All the patients had colorectal cancer with liver metastasis and $40 \%$ of them had prior evidence of metastasis at another site that was not recovered at the time they were included. The majority of them had a WHO performance status of 0 (70\%) and had received 2 or more lines of chemotherapy (80\%). A total of 92 urinary samples were analysed. St2 involved 16 patients who received a chronochemotherapy protocol. The majority of the patiens had a colon cancer (69\%) with liver metastasis (75\%). $94 \%$ of them had prior resection of the primary tumor, and $63 \%$ of them also had prior metastases surgery. The majority of them (88\%) had received more than 2 lines of chemotherapy. A total of 239 urinary samples were analysed. St3 recruited 30 patients, the majority of whom had a WHO performance status of 0 (76.7\%), primary colon cancer (66.7\%), and liver metastases (86.7\%). Thirteen patients had two or more metastatic sites (43\%). All but one patient had received prior chemotherapy, with 2 prior protocol lines being administered for $93.3 \%$ of the patients. Sixteen patients (53.8\%) had undergone prior surgery of metastases. Wrist watch monitoring was complete for 28 out of 30 patients over 5 days (93.3\%). There were two technical failures, with no data collection. Two hundred and ninety-three urine samples were collected by the 30 patients. The number of samples was insufficient for a single patient. Overall, a total of 226 nucleoside excretion data points were exploitable for the analysis of 29 patients, corresponding to a protocol compliance rate of $95.9 \%$. Overall, nucleosides excretions were determined in 557 urinary samples in the three studies.

\section{Overnight nucleosides excretions in the absence of treatment}


Within each St, the early morning levels of urinary nucleoside excretion, corresponding to overnight elimination into the urine, varied by up to nearly 100 -fold according to nucleoside type in the absence of any treatment for the past 2 weeks (Figure 2). The excretion of pseudouridine was nearly 10-fold as large as those of 1-methylguanosine, 1-methyladenosine and N2-N2dimethylguanosine, and 20-30 fold as large as those of 4-acetylcytidine and 1-methylinosine. The nucleosides with lowest excretions were adenosine and cytidine. Interpatient variability was large with coefficients of variation ranging from $122 \%$ for cytidine in St 1 to $21.8 \%$ for 4-acetylcytidine in St 2, with a median value of 36.9\% [IQR, 28.2 to 59.5\%] across nucleosides and studies. Pairwise Spearman correlations revealed that the overnight excretion of pseudourine was higher in patients with comorbidities $(p=0.01)$, that of 1 -methyladenosine was higher in female as compared to male patients $(p<0.001)$, and that of adenosine was higher in those patients with primary colon rather than rectum cancer $(p=0.01)$.

\section{Changes after hepatectomy and relations with outcomes}

All the patients in St1 had macroscopically complete liver metastases resections, that were categorised as R0 for 4 patients, and R1 for 6 patients. Histopathologic assessement revealed $>50 \%$ necrosis or fibrosis of all the metastatic lesions in the resected liver. Linear regression analysis was applied to identify increase/decrease ( $p$-value $\leq 0.05)$ and no change $(p>0.05)$ of nucleosides excretions over time. No consistent changes were found for the overnight urinary excretions of nucleosides over the week following partial hepatectomy. Rather, the urinary excretions of 1-methylguanosine, 1-methyladenosine, adenosine and/or cytidine remained similar in seven patients, or increased in three patients, all with R1 resection, over the week following hepatectomy. The increased nucleosides excretions were recapitulated in methylguanosine, and were associated with prolonged survival or apparent cure. Thus 3 of the 6 patients with R1 hepatectomy, who showed a significant increase in 1-methylguanosine are alive at 4.5 years after surgery, while the other three R1 patients with no significant change in 1-methylguanosine died within the 2 years following surgery. In contrast, there was no significant increase in nucleosides excretion in the 4 R0 patients. Trends in 1-methylguanosine excretions are shown as examples in one R1 and one R0 patient (Figure S2)..

\section{Changes after chronochemotherapy, and relations with outcomes}

In 15/16 St2 patients with nucleosides measures (1 of them had not urinary excretion usable datas), chronochemotherapy administration was followed with increasing or decreasing trends in overnight urinary nucleosides excretions in six patients (see two illustrative examples for cytidine in Figure S3) or no change in nine patients. The data thus highlighted patient-specific treatment responses and dynamics, which were recapitulated by the changes in 1-methylguanosine, acetylcytidine, adenosine and cytidine. Having an increasing trend (slope of regression line with p-value $\leq 0.05$ ) in these urinary nucleosides after chemotherapy was associated with a $>50 \%$ subsequent increase in plasma CEA (Fisher's exact test p-value $=0.028$ ) and a poor survival (Table 2). Only 14/16 patients were analysed, 2 of them had no CEA datas available. In contrast, no change $(p>0.05)$ in nucleosides was associated with no change or decreasing CEA, no toxicity > Grade 1, and better survival.

\section{Twenty-four hour changes in urinary nucleosides excretions}

In St 3, detectable urinary levels were found in all the patients for eight nucleosides, but not for 8-hydroxy-2'-deoxyguanosine.

\section{Average 24-h excretions (mesors)}

The median level of urinary nucleoside excretion mesors in the 29 patients varied by up to 110 -fold according to nucleoside type (Figure 3.1). Thus, the excretion of pseudouridine (median, $64.3 \mu \mathrm{g} / \mathrm{g}$ of creatinine) was nearly 10 -fold as large as those of 1methylguanosine, 1-methyladenosine and N2-N2-dimethylguanosine, and 20-30 fold as large as those of 4-acetylcytidine and 1methylinosine. The nucleosides with lowest excretions were adenosine and cytidine (medians of 0.69 and $0.61 \mu \mathrm{g} / \mathrm{g}$ of creatinine respectively). Large inter-patient variations were demonstrated for the urinary excretion of the modified nucleosides, with coefficients of variation ranging from $25.0 \%$ (pseudouridine) to $42.3 \%$ (1-methylguanosine). 
The mesors of nucleosides excretion were correlated among patients, except for cytidine. More specifically, two groups of correlated nucleosides were identified (Figure 3.2).. A first one, involving pseudouridine, 1-methyladenosine, 1-methylinosine, and adenosine, and a second one involving 1-methylguanosine, N2-N2-dimethylguanosine and 4-acetylcytidine.

\section{Twenty-four-hour patterns}

Using multiple-component cosinor analysis, the number of nucleoside excretion rhythms per patient ranged from null to 7, with a median of 3. Raw nucleosides measurements and cosinor model fitting are shown as examples for three patients (A, B and C) (Figure 4). Compared with the relatively flat fitting curves for patient $B$ and $C$, patient $A$ displayed a large circadian variability in nucleosides excretion and consistent day-to-day patterns. As a result, patient A had rhythmic excretions for 7 nucleosides, with significantly reproducible 24-hour patterns (plotted with solid lines), while patient $B$ had 3 excretion rhythms and patient $C$ a single one.

Overall, the urinary excretion of each nucleoside displayed a 24-h rhythm for $23.1 \%$ of the patients for 4-acetylcytidine up to $37.9 \%$ of the patients for pseudouridine. A 12-h rhythm was found for $17.2 \%$ of the patients for both 1-methylguanosine and 1methyladenosine, up to $24.1 \%$ of the patients for pseudouridine. Thus a $24-\mathrm{h}$ and/or a 12 -h rhythm characterized pseudouridine urinary excretion for $48.3 \%$ of the patients (highest rate) as compared to 4 -acetylcytidine for $34.6 \%$ of the patients (lowest rate).

Statistically significant correlations were found for the urinary excretion rhythm amplitudes as $\%$ of mesor for 1-methylinosine (Spearman's correlation with $p$-value $=0.001)$, 1-methylguanosine $(p<0.001), 1$-methyladenosine $(p=0.004)$, N2-N2-

dimethylguanosine $(p<0.001)$, cytidine $(p<0.001)$ and 4-acetylcytidine $(p=0.017)$. Circadian mesor, amplitude and acrophase estimates for the eight nucleosides excretions are summarised in Table 3.

\section{Circadian patterns in rest-activity}

The 24-hour pattern in rest-activity of the 28 patients in St 3 ranged from robust to weak as indicated by the results from Hidden Markov modelling, dichotomy index $\mathrm{K}<0$, autocorrelation coefficient $\mathrm{r} 24$, circadian period estimates and 24-h cosinor estimates of amplitude and acrophase (Table S1).. Interestingly, the median $\mathrm{k}<0$ value was $97.9 \%$, in good agreement with prior studies on larger sample sizes, where this value was $97.5 \%[28]$. Interpatient differences in rest-activity patterns were obvious (Figure 5).. The timeseries of wrist-watch activity measurements (Figure 5(1)), the corresponding displays resulting from HMM (Figure 5(2)), and the temporal distribution of High, Intermediate and Low Activities over the 24h (Figure 5(3)) are shown for the same three patients as those taken as illustrative examples for nucleosides rhythmic excretions (Figure 4).. Patient B had a regular and robust rhythm, patient $\mathrm{C}$ had a severely disturbed pattern and patient $\mathrm{A}$ displayed an intermediate profile.

The dichotomy index $1<0$, the Rhythm Index, the transition probability of remaining in IA state $(\mathrm{p} 1-1)$, and the autocorrelation coefficient at 24-h ( $(24)$ were strongly correlated with each other as the Spearman rank coefficients $\rho$ were ranging from $0.49(p=$ $0.009)$ for $k 0$ and the Rhythm Index, to $0.80(p<0.001)$ for $k 0$ and $p 1-1$. The median level of the HA state was also correlated with $\mathrm{k}<0(\rho=0.40$ with $p=0.033)$ and $\mathrm{r} 24(\rho=0.58$ with $p=0.001)$, while the overall daily rest duration was negatively correlated with the Rhythm Index $(\rho=-0.49$ with $p=0.007)$ (Figure S4).

Multivariate regression analysisrevealed that a good performance status ( $P S=0)$ was significantly associated with high $1<0(p=$ $0.007)$, high $p 1-1(p<0.001)$, and high Rhythm Index $(p=0.007)$. Female sex was also found be associated with high values in $\mathrm{p} 1-1(\mathrm{p}=0.024)$ and median activity at HA state $(\mathrm{p}=0.011)$, and possibly high values in $\mathrm{k}<0$ a nd $\mathrm{r} 24(0.05 \leq \mathrm{p}<0.1)$.

\section{Relations of nucleosides excretion changes with patient characteristics and rest- activity pattern}

In St 3, multivariate regression analysis showed that the mesor of 1-methylguanosine excretion was higher in patients with a performance status of 1 as compared to those whose PS was $0(p=0.026)$. Themesor of pseudo uridine and that of adenosine 
were lower in the patients who had prior liver metastases surgery $(p=0.049$ and $p=0.007$, respectively). The circadian amplitudes of adenosine and N4-acetylcytidine were higher in female as compared to male patients $(p=0.011$ and $p=0.01$, respectively).

Spearman's rank correlation analysis revealed striking relations between the relative circadian amplitude of urinary nucleosides excretions 24-hour patterns and rest-activity indices (Figure 6). For example, the larger the rest duration, the larger the relative circadian amplitude of pseudouridine $(p=0.015)$, adenosine $(p=0.049)$, 4-acetylcytidine $(p=0.008)$ and cytidine $(p=0.002)$.

\section{Discussion}

In patients with previously treated metastatic colorectal cancer, the average overnight urinary excretions of six modified nucleosides varied by over 100-fold according to the nucleoside considered, being highest for pseudouridine, intermediate for 1methyladenosine, 1-methylguanosine and 4-acetylcytidine, and lowest for cytidine and adenosine. Large differences were found between patients before liver surgery or chronochemotherapy, as well as along the 24-hours scale, that partly related to sex, comorbidities, and primary colon or rectum site.

Consistently with our findings, large between- and within-patients variations were reported for pseudouridine, 1-methyladenosine and 1-methylguanosine in patients with breast, lung, or gastric cancer. In these patients however cytidine and adenosine urinary excretions were larger, and 4-acetylcytidine was only occasionally determined [10, 11, 41].

In our study, both complete liver metastases resection and chronochemotherapy resulted in patient-specific responses in the overnight urinary excretions of the six modified nucleosides. Increasing, stable, or decreasing trends were captured in the urinary excretions of 1-methylguanosine, 1-methyladenosine, adenosine and cytidine for all the patients in St1 or St2. Consistent increases in urinary nucleosides excretions were related to both R1 metastases resections and prolonged survival or cure in the hepatectomy patients (St1), but to disease progression on chronochemotherapy (St2). These observations suggest the tight links between these four urinary nucleosides levels and cellular proliferation, this calling for further testing as early markers of efficacy of metastases surgery and chemotherapy.

The 24-hour mesors of urinary excretion levels of the modified nucleosides in St3 ranked similarly as the overnight excretions that were determined in each study. Eight-hydroxy-2-deoxyguanosine, the ninth modified nucleoside selected for St3, was not detected in $68 \%$ of the diluted urine samples. A circadian rhythm in the urinary excretion of this oxidized form of guanosine had been previously reported both in healthy adults and in patients with multiple sclerosis, but not in diabetic patients[42,43]. Moreover, elevated levels of 8-hydroxy-2-deoxyguanosine were reported in cancer patients[34,44]. Here, owing to the dilution of the samples before injection, this modified nucleoside was only identified in $32 \%$ of the urine samples and close to the limit of quantification.

Robust correlations were found between the mesor values of pseudouridine, 1-methyladenosine, 1-methylinosine, and adenosine, on the one hand, and between those of 1-methylguanosine, N2-N2-dimethylguanosine and 4-acetylcytidine on the other hand. Cytidine excretion appeared as independent from that of the other nucleosides.

Circadian and/or 12-hour rhythms characterized the urinary excretion of pseudouridine for $48.3 \%$ of the patients (highest rate) and that of 4 -acetylcytidine for $34.6 \%$ of the patients (lowest rate). Individual patients displayed marked rhythmic excretion patterns for up to seven nucleosides. Interestingly, the relative circadian amplitudes of nucleosides excretions were positively associated with the duration of rest for pseudouridine, adenosine, 4-acetylcytidine and cytidine, and with the dichotomy index $\mid<0$ for 1-methylguanosine (Spearman correlation, $p<0.05$ ). These results suggested that rhythmic excretion patterns of modified nucleosides could reflect a host-mediated circadian control of cancer progression. Indeed, progression-free survival and overall survival were significantly improved in metastatic colorectal cancer patients whose $<0$ exceeded $97.5 \%[14]$. This finding has been confirmed in other oncological clinical settings[45, 46].

A main limitation of our work involves the limited sample size in St1 and 2. Healthy controls would also be needed for establishing the physiological relations between host circadian biomarkers and the rhythmic turnover of nucleic acids in healthy tissues, as reflected in the urinary excretions of the modified nucleosides. A circadian rhythm was documented in healthy adults

Page 8/18 
for both 8-hydroxy-2'-deoxyguanosine, with high values in the afternoon [43], and for pseudouridine and N2-N2dimethylguanosine, with highest excretions occurring between 06:00 and 12:00 [47]. Purine and pyrimidine synthesis and catabolism are rhythmically controlled by the circadian clock in mouse liver[489]. Clock gene Bmal1 silencing ablated these metabolic rhythms. Such Bmal1 silencing could result from host circadian disruption, as shown in mice on chronic jet lag[49]. Here, host circadian disruption was determined using 5-day time series of rest-activity monitoring. The median value of the dichotomy index $1<0$ in our patient population was $97.9 \%$, as compared to $97 . \%$ for our prior cohorts of metastatic colorectal cancer patients, where this parameter was shown as an independent prognostic indicator of progression-free and overall survival[29]. $1<0$ was here correlated with the circadian amplitude of 1-methylguanosine, and it was significantly inter-correlated with other rest-activity parameters that helped assess circadian timing system function in individual patients. The duration of rest over the 24 hours was the host parameter, that displayed the strongest links with the rhythmic excretions of modified nucleosides, suggesting that the nucleic acids turnover pattern over the 24 hours could be predominantly tied to the rest span. However, such correlations were not significant in the additional bootstrap uncertainty check, with $90^{\text {th }}$ quantiles of Spearman correlation p-value $>0.1$, a finding supporting the need for confirmation within a larger sample size. Interestingly, however, short sleep duration has been found to be associated with higher mortality in a large cohort of colorectal cancer survivors [50].

In conclusion, we identified and ranked the main modified nucleosides that are excreted into the urines of patients with colorectal cancer metastases. Large interpatient variations were identified, that could reflect tumour or host nucleic acids turnover. Intrapatient changes in urinary nucleosides excretions over the 24-hours were partly related to the circadian rhythm in restactivity. The clinical relevance of urinary nucleosides excretions as biomarkers was further supported by the association of 1methylguanosine excretion after R1 hepatectomy with prolonged survival, and that of early increases in modified nucleosides despite chemotherapy with disease progression and poor survival.

\section{Declarations}

\section{ETHICAL APPROVAL AND CONSENT TO PARTICIPATE}

The studies were sponsored by the National Institute for Health and Medical Research of France (INSERM), approved by the Ethics Committee of Kremlin Bicetre hospital (France) and registered with clinical trial numbers NCT01693848, NCT01693861 and NCT01693835, respectively for Study 1, 2 and 3. They were conducted according to the "Ethics and methods for biological rhythm research on animals and human beings" and complied with the in force declaration of Helsinki principles [51].

All the patient provided a signed informed consent for their participation.

\section{DATA AVAILABILITY}

\section{All the data could be available on demand to the corresponding author.}

\section{FUNDING}

Supported by grant CANCERSENSOR ANR-10-TECS-0004 2011-2015, and ARTBC International, Villejuif, France. Qi Huang, Francis Lévi, and Barbel Finkenstadt are supported by the Medical Research Council, London, UK (Award Number: Grant MR/M013170.

\section{AUTHOR CONTRIBUTION}

Dulong S (DS), Huang Q (HQ), Innominato P F (IPF), Karaboue A (KA), Bouchahda M (BM), Pruvost A (PA), Théodoro F (TF), Agrofoglio $L A(A L A)$, Adam R (AR), Finkenstädt B (FB), and Lévi F (LF) contributed to the work as follows: Conceptualization and design of the clinical study (DS, LF, IPF, AR); patients recruitment (LF, AR, IPF, BM); study conduct (DS, AK); nucleosides quantification (PA, TF); data collection and organisation (DS, AK, HQ), mathematical and statistical analyses (HQ, FB, LF); first 
draft manuscript writing (DS, HQ, LF); review and editing (all); funding acquisition (DS,LF, PA, ALA); project administration (DS, LF, $K A)$.

\section{CONFLICT OF INTEREST}

The authors declare no conflict of interest

\section{References}

1. Locker GY ${ }^{1}$,Hamilton S, Harris J, Jessup JM, Kemeny N, Macdonald JS, Somerfield MR, Hayes DF, Bast RC Jr; ASCO 2006 update of recommendations for the use of tumor markers in gastrointestinal cancer. J Clin Oncol. 2006 Nov 20;24(33):531327. Epub 2006 Oct 23.

2. Wills $B^{1}$, Gorse $E^{2}$, Lee $V^{3}$.Role of liquid biopsies in colorectal cancer. Curr Probl Cancer.2018 Aug 29. pii: S01470272(18)30071-0. doi: 10.1016/j.currproblcancer.2018.08.004. [Epub ahead of print]

3. Nakano K, Nakao T, Schram KH, Hammargren WM, McClure TD, Petersen E. Urinary excretion of modified nucleosides as biological marker of RNA turnover in patients with cancer and AIDS. Clin. Chim. Acta 1993, 218, 169

4. Jeng LB, Lo WY, Hsu WY, Lin WD, Lin CT, Lai CC, Tsai FJ. Analysis of urinary nucleosides as helper tumor markers in hepatocellular carcinoma diagnosis. Rapid Comm. MassSpectro. 2009, 23, 1543

5. Sasco AJ, Rey F, Reynaud C, Bobin JY, Clavel M, Nivelau A. Breast cancer prognostic significance of some modified urinary nucleosides. Cancer Lett. 1996, 108, 157.

6. Henneges C, Bullinger D, Fux R, Friese N, Seeger H, Neubauer H, Laufer S, Gleiter C H, Schwab M, Zell A et al. Prediction of breast cancer by profiling of urinary RNA metabolites using Support Vector Machine-based feature selection. BMC Cancer 2009, 9, No pp.

7. Cho SH, Choi MH, Lee WY, Chung BC. Evaluation of urinary nucleosides in breast cancer patients before and after tumor removal. Clin. Biochem. 2009, 42, 540.

8. Yang J, Xu G, Kong H, Zheng Y, Pang T, Yang Q. Artificial neural network classification on high performance liquid chromatography of urinary and serum nucleosides for the clinical diagnosis of cancer. J. Chromatogr. B 2002, 780, 27.

9. Limbach PA, Crain PF, McCloskey JA,Summary : the modified nucleosides of RNANucleic Acids Res 1994 Jun25; 22(12): 2183-2196

10. Seidel A, Brunner S, Seidel P, Fritz GI, Herbarth O. Modifed nucleosides: an accurate tumour marker for clinical diagnosis of cancer, early detection and therapy control. British J. Cancer 2006, 94, 1726

11. Opitz $P^{1}$, Herbarth $O^{2,3}$, Seidel $A^{2}$, Boehm $A^{4}$, Fischer $M^{4}$, Mozet $C^{4}$, Dietz $A^{3,4}$, Wichmann $G^{3}$ Modified Nucleosides - Molecular Markers Suitable for Small-volume Cancer?Anticancer Res.2018 Nov;38(11):6113-6119. doi: 10.21873/anticanres.12962.

12. Focan C, Focan-Henrard D, Frere MH, Le Hung S, Castronovo V,Colleite J,Franchimont P,Touitou Y Levi F, Roemeling RW AND Hrushesky WJ. Circadian CEA variability: when to sample? J. Clin. Oncol. 1986 , 4, 607-60

13. Touitou, Y., Bogdan, A., Levi, F., Benavides, M. and Auzeby, A., Disruption of the circadian patterns of serum cortisol in breast and ovarian cancer patients: relationships with tumour marker antigens. J. Cancer, 1996, 74, 1248-1252.

14. Touitou, Y., Levi, F., Bogdan, A., Benavides, M., Bailleul, F., and Misset, J.L., Rhythm alteration in patients with metastatic breast cancer and poor prognostic factors. Cancer Res. clin. Oncol., 1995, 121, 181-188.

15. Zinneman HH, Halberg F, Haus E, Kaplan M. Circadian rhythms in urinary light chains, serum iron and other variables ofmultiple myeloma patients. Int J Chronobiol. 1974;2(1):3-16.

16. Lévi F, Okyar A, Dulong S, Innominato PF, Clairambault J Circadian timing in cancer treatments.Annu Rev Pharmacol Toxicol. 2010;50:377-421.

17. Sulli G, Manoogian ENC, Taub PR, Panda S Training the CircadianClock, Clocking the Drugs, and Drugging the Clock to Prevent, Manage, and Treat Chronic Diseases. Trends Pharmacol Sci. 2018 Sep;39(9):812-827 
18. Lemmer B, Oster H.The Role of CircadianRhythms in the Hypertension of Diabetes Mellitus and the Metabolic Syndrome. Curr Hypertens Rep. 2018 May 5;20(5):43.

19. Innominato PF, Roche VP, Palesh OG, Ulusakarya A, Spiegel D, Lévi FA. The circadian timing system in clinical oncology. . Ann Med.2014 Jun;46(4):191-207. doi: 10.3109/07853890.2014.916990.

20. Bass J, Lazar MA. Circadian time signatures of fitness and disease. 2016 Nov 25;354(6315):994-999.

21. HonmaS The mammalian circadian system: a hierarchical multi-oscillator structure for generating circadian J Physiol Sci. 2018 May;68(3):207-219

22. Gaucher J, Montellier E, Sassone-Corsi P. Molecular Cogs: Interplay between Circadian Clock and Cell Cycle. Trends Cell Biol.2018 May;28(5):368-379. doi: 10.1016/j.tcb.2018.01.006. Epub 2018 Feb 19.

23. KamagataM, Ikeda Y, Sasaki H, Hattori Y, Yasuda S, Iwami S, Tsubosaka M, Ishikawa R, Todoh A, Tamura K, Tahara Y, Shibata S Potent synchronization of peripheral circadian clocks by glucocorticoid injections in PER2::LUC-Clock/Clock mice. Chronobiol Int. 2017;34(8):1067-1082

24. BalsalobreA, Brown SA, Marcacci L, Tronche F, Kellendonk C, Reichardt HM, Schütz G, Schibler U.Resetting of circadian time in peripheral tissues by glucocorticoid signaling.Science. 2000 Sep 29;289(5488):2344-7

25. BalsalobreA, Marcacci L, Schibler U Multiple signaling pathways elicit circadian gene expression in cultured Rat-1 fibroblasts. Curr Biol. 2000 Oct 19;10(20):1291-4

26. Brown SA, Zumbrunn G, Fleury-Olela F, Preitner N, Schibler U.Rhythms of mammalian body temperature can sustain peripheral circadian Curr Biol. 2002Sep 17;12(18):1574-83

27. BuhrED, Yoo SH, Takahashi JS. Temperature as a universal resetting cue for mammalian circadian Science. 2010 Oct 15;330(6002):379-85.

28. Lévi F, Dugué PA, Innominato P, Karaboué A, Dispersyn G, Parganiha A, Giacchetti S, Moreau T, Focan C, Waterhouse J, Spiegel D; ARTBC Chronotherapy Group. Wrist actimetrycircadian rhythm as a robust predictor of colorectal cancer patients survival. Chronobiol Int. 2014 Oct;31(8):891-900. doi: 10.3109/07420528.2014.924523. Epub 2014 Jun 13

29. NataleV, Innominato PF, Boreggiani M, Tonetti L, Filardi M, Parganiha A, Fabbri M, Martoni M, Lévi F. The difference between in bed and out of bed activity as a behavioral marker of cancer patients: A comparative actigraphic study.Chronobiol Int. 2015;32(7):925-33

30. Lévi F., Karaboué A., Gorden L., Innominato P. F., Saffroy R.I, Giacchetti S., Hauteville D., Guettier C., Adam R., Bouchahda M. : Cetuximab and circadian chronomodulated chemotherapy as salvage treatment for metastatic colorectal cancer (mCRC): safety, efficacy and improved secondary surgical resectability. Cancer Chemother. Pharmacol.,_2011, 67 (2): 339-348.

31. Agrofoglio LA, Krstulja A, De Schutter C, Favetta P, Delepee R, Roy V, Dejous C, Hallil H, Lachaud JL, Lebal N, Omar Aouleb N, Raimbault V, Rebiere D, Dulong S, Levi F, Junot C, Theodoro F, Pruvost A, Vidal R. Detection of urinary modified nucleosides by bulk acoustic wave MIP sensor - Results and future work. IRBM,2014, 35(2) 66-71.

32. ema.europa.eu/docs/enGB/documentlibrary/Scientificguideline/2011/08/WC500109686.pdf

33. Huang Q, Cohen D, Komarzynski S, et al. Hidden markov models for monitoring circadian rhythmicity in telemetric activity data. Journal of The Royal Society Interface. Epub ahead of print 2018.

34. van der Waals $\mathrm{LM}^{1}$, Jongen $\mathrm{JMJ}^{1}$, Elias SG${ }^{2}$, Veremiyenko $\mathrm{K}^{1}$, Trumpi $\mathrm{K}^{1}$, Trinh $\mathrm{A}^{3}$, Laoukili $\mathrm{J}^{1}$, Ubink $\mathrm{I}^{1}$, Schenning-van Schelven $\mathrm{SJ}^{1}$, van Diest PJ ${ }^{4}$, Borel Rinkes $\mathrm{IHM}^{1}$, Kranenburg $\mathrm{O}^{5}$. Increased Levels of Oxidative Damage in Liver Metastases Compared with Corresponding Primary Colorectal Tumors: Association with Molecular Subtype and Prior Treatment. Am J Pathol. 2018 Oct;188(10):2369-2377. doi: 10.1016/j.ajpath.2018.06.008. Epub 2018 Jul 20.

35. InnominatoPF ${ }^{1,2,3}$, Komarzynski $S^{2,3}$, Palesh $\mathrm{OG}^{4,5}$, Dallmann $\mathrm{R}^{2}$, Bjarnason $\mathrm{GA}^{6}$, Giacchetti $S^{3,7}$, Ulusakarya $A^{3,8}$, Bouchahda $M^{3,8,9}$, Haydar $M^{8}$, Ballesta $A^{2,3,10}$, Karaboué $A^{11}$, Wreglesworth $\mathrm{NI}^{1}$, Spiegel $D^{4,5}$, Lévi $F A^{2,3,8}$. Circadian rest-activity rhythm as an objective biomarker of patient-reported outcomes in patients with advanced cancer. Cancer Med. 2018 Sep;7(9):43964405. doi: 10.1002/cam4.1711. Epub 2018 Aug

36. Costa MJ, Finkenstä dt B, Roche V, Lé vi F, Gould PD, Foreman J, Halliday K, Hall A, Rand DA. 2013 Inference on periodicity of circadian time series. Biostatistics 14, $792-806$ 
37. Cornelissen, Germaine. "Cosinor-based rhythmometry." Theoretical Biology and Medical Modelling1.16, 2004.

38. Pinheiro J, Bates D, DebRoy S, Sarkar D and R Core Team (2018). nlme: Linear and Nonlinear Mixed Effects Models. R package version 3.1-137, https://CRAN.R-project.org/package=nlme.

39. Zoubir, Abdelhak M., and D. Robert Iskander. Bootstrap techniques for signal processing. Cambridge University Press, 2004.

40. Zhang Z. Variable selection with stepwise and best approaches Ann transl Med 2016 Apr;4(7):136. doi: 10.21037/atm.2016.03.

41. Hsu WY, CJ, Huang YC, Tsai FJ, Jeng LB andLai CCUrinary Nucleosides as Biomarkers of Breast, Colon, Lung, and Gastric Cancer in Taiwanese PLoS One. 2013; 8(12): e8170j

42. Kanabrocki EL ${ }^{1}$,Murray D, Hermida RC, Scott GS, Bremner WF, Ryan MD, Ayala DE, Third JL, Shirazi P, Nemchausky BA, Hooper DC. Circadian variation in oxidative stress markers in healthy and type Il diabetic men. Chronobiol Int. 2002 Mar;19(2):423-39

43. KanabrockiEL ${ }^{1}$, Ryan MD, Murray D, Jacobs RW, Wang J, Hurder A, Friedman NC, Siegel G, Eladasari B, Nemchausky BA, Cornelissen G, Halberg F. Circadian variation in multiple sclerosis of oxidative stress marker of DNA damage. A potential cancer marker? Clin Ter. 2006 Mar-Apr;157(2):117-22.

44. Guo $C^{1}$, Li X $X^{1}$, Wang $R^{1}$, Yu J1, Ye $M^{1,2}$, Mao $L^{1,3}$, Zhang $S^{1}$, Zheng $S^{1}$. Association between Oxidative DNA Damage and Risk of Colorectal Cancer: Sensitive Determination of Urinary 8-Hydroxy-2'-deoxyguanosine by UPLC-MS/MS Analysis. Sci Rep. 2016 Sep 2;6:32581. doi: 10.1038/srep32581.

45. Kuo LC ${ }^{1}$, Chang WP, Huang HC, Lin CC. Association of Time-Varying Rest-Activity Rhythm With Survival in Older Adults With Lung Cancer. Cancer Nurs.2018 Oct 5. doi: 10.1097/NCC.0000000000000647. [Epub ahead of print]

46. Chang $W P^{1,2}$, Smith $\mathrm{R}^{3}$, Lin $C C^{2,3,4}$. Age and rest-activity rhythm as predictors of survival in patients with newly diagnosed lung cancer.Chronobiol Int.2018 Feb;35(2):188-197. doi: 10.1080/07420528.2017.1391278. Epub 2017 Nov 16

47. ToppH ${ }^{1}$, Unverzagt S, Rudloff S, Schöch G, Manz F, Fusch C.Diurnal variation in the renal excretion of modified RNA catabolites in humans. Clin Sci (Lond). 2003 Aug;105(2):195-202.

48. FustinJM, Doi M, Yamada H, Komatsu R, Shimba S, Okamura H. Rhythmic nucleotide synthesis in the liver: temporal segregation of metabolites. Cell Rep. 2012 Apr 19;1(4):341-9.

49. FilipskiE, Innominato PF, Wu M, Li XM, lacobelli S, Xian LJ, Lévi F.Effects of light and food schedules on liver and tumor molecular clocks in mice. J Natl Cancer Inst. 2005 Apr 6;97(7):507-17

50. Xiao $Q^{1}$, Arem $H^{2}$, Pfeiffer $\mathrm{R}^{3}$, Matthews $\mathrm{C}^{3}$.Prediagnosis Sleep Duration, Napping, and Mortality Among Colorec tal Cancer Survivors in a Large US Cohort. 2017 Apr 1;40(4). doi: 10.1093/sleep/zsx010

51. Portaluppi F, Smolensky MH, Touitou Y. Ethics and methods for biological rhythm research on animals and human beings.Chronobiol Int. 2010 Oct;27(9-10):1911-29

\section{Tables}




\begin{tabular}{|c|c|c|c|}
\hline & St1 & St2 & St3 \\
\hline Number of patients & 10 & 16 & 30 \\
\hline \multicolumn{4}{|l|}{ Sex } \\
\hline Male & 5 & 8 & 18 \\
\hline Female & 5 & 8 & 12 \\
\hline \multicolumn{4}{|l|}{ Age, years } \\
\hline Median & 68.7 & 67.5 & 66.2 \\
\hline Range & $23-76$ & $44-81$ & $23-74$ \\
\hline \multicolumn{4}{|l|}{ Performance status (WHO) } \\
\hline 0 & 7 & 12 & 23 \\
\hline 1 & 3 & 4 & 7 \\
\hline \multicolumn{4}{|l|}{ Primary site } \\
\hline Colon & 8 & 11 & 20 \\
\hline Rectum & 2 & 5 & 10 \\
\hline \multicolumn{4}{|l|}{ Metastatic site } \\
\hline Liver & 10 & 12 & 22 \\
\hline Lung & 3 & 8 & 10 \\
\hline Others & 1 & 10 & 18 \\
\hline \multicolumn{4}{|l|}{ Number of metastatic sites } \\
\hline 1 & 7 & 6 & 17 \\
\hline 2 & 2 & 3 & 6 \\
\hline 3 & 1 & 7 & 7 \\
\hline \multicolumn{4}{|l|}{ Comorbidities } \\
\hline Yes & 5 & 10 & 14 \\
\hline No & 5 & 6 & 16 \\
\hline \multicolumn{4}{|l|}{ Prior primary tumor surgery } \\
\hline Yes & 9 & 15 & 27 \\
\hline No & 1 & 1 & 3 \\
\hline \multicolumn{4}{|l|}{ Prior metastatic surgery } \\
\hline Yes & 6 & 10 & 16 \\
\hline No & 4 & 6 & 14 \\
\hline \multicolumn{4}{|l|}{ Number of prior chemotherapy lines } \\
\hline 0 & 0 & 0 & 1 \\
\hline 1 & 2 & 2 & 1 \\
\hline $2-3$ & 7 & 11 & 22 \\
\hline More than 3 & 1 & 3 & 6 \\
\hline \multicolumn{4}{|l|}{ Prior chemotherapy modality } \\
\hline Chronotherapy & 3 & 12 & 23 \\
\hline Conventional & 7 & 4 & 7 \\
\hline \multicolumn{4}{|l|}{ Plasma CEA (mg/L) } \\
\hline$<5$ & 5 & 3 & 6 \\
\hline $6-100$ & 3 & 10 & 17 \\
\hline$>100$ & 0 & 2 & 4 \\
\hline Unknown & 2 & 1 & 3 \\
\hline
\end{tabular}

Table 1: Main characteristics of the patients in each study (St)

\begin{tabular}{|l|l|l|l|l|}
\hline \multicolumn{1}{|c|}{ CEA } & Increase & No change & Decrease & Sum \\
Nucleosides & & & & \\
\hline Increase & 2 & 0 & 0 & 2 \\
\hline No change & 0 & 8 & 1 & 9 \\
\hline Decrease & 1 & 2 & 0 & 3 \\
\hline Sum & 3 & 10 & 1 & 14 \\
\hline
\end{tabular}

Table 2 
Nucleosides versus carcinoembryonic antigen (CEA) for patients in St 2. Fourteen patients with both nucleosides and CEA information are involved. Change of CEA are classified as increase or decrease if the CEA was increased or decreased by more than 50\% 1-2 months after the chronochemotherapy, and no change if neither the cases. Change of nucleosides are classified by increase or decrease if any nucleoside excretion time series was identified as increasing or decreasing over time (slope of regression line with p-value 0.05 ), and no change if p-value 0.05 .

\begin{tabular}{|c|c|c|c|c|c|c|c|c|}
\hline & $\begin{array}{c}1- \\
\text { methylinosine } \\
\end{array}$ & pseudouridine & $\begin{array}{c}1- \\
\text { methylguanosine }\end{array}$ & $\begin{array}{c}1- \\
\text { methyladenosine } \\
\end{array}$ & $\begin{array}{c}\text { N2-N2- } \\
\text { dimethylguanosine }\end{array}$ & adenosine & cytidine & $\begin{array}{c}4- \\
\text { acetylcytidine }\end{array}$ \\
\hline $\begin{array}{l}\text { of } \\
s\end{array}$ & 29 & 29 & 29 & 29 & 28 & 28 & 28 & 26 \\
\hline $\begin{array}{l}\text { of } \\
\text { vith } \\
\text { int } \\
\text { ity } \\
\text { a }\end{array}$ & 7 & 11 & 10 & 10 & 9 & 9 & 10 & 6 \\
\hline \multirow[t]{2}{*}{ nine) } & $\begin{array}{l}2.41(0.99- \\
4.67)\end{array}$ & $\begin{array}{l}66.1(33.8- \\
97.9)\end{array}$ & $\begin{array}{l}7.44(1.97- \\
15.04)\end{array}$ & $\begin{array}{l}6.57(0.86- \\
9.18)\end{array}$ & $\begin{array}{l}6.70(2.19- \\
12.11)\end{array}$ & $\begin{array}{l}0.69 \\
(0.18- \\
1.41)\end{array}$ & $\begin{array}{l}0.61 \\
(0.26- \\
1.13)\end{array}$ & $\begin{array}{l}3.09(0.31- \\
5.80)\end{array}$ \\
\hline & $\begin{array}{c}2.32 \text { [1.90, } \\
2.63]\end{array}$ & $\begin{array}{c}64.3 \text { [53.6, } \\
80.2]\end{array}$ & $7.22[1.97,9.08]$ & $6.84[5.27,7.95]$ & $6.35[5.16,8.31]$ & $\begin{array}{r}0.69 \\
{[0.51} \\
0.91] \\
\end{array}$ & $\begin{array}{r}0.58 \\
{[0.44} \\
0.72]\end{array}$ & $\begin{array}{c}3.11[2.46 \\
3.73]\end{array}$ \\
\hline \multirow[t]{2}{*}{$\begin{array}{l}\text { de } \\
\text { nine) }\end{array}$} & $\begin{array}{l}0.98(0.21- \\
2.95)\end{array}$ & $\begin{array}{l}26.9(5.74- \\
60.7)\end{array}$ & $\begin{array}{l}5.57(1.02- \\
16.36)\end{array}$ & $\begin{array}{l}1.94(0.66- \\
4.69)\end{array}$ & $\begin{array}{l}5.63(0.38- \\
21.48)\end{array}$ & $\begin{array}{l}0.39 \\
(0.08- \\
1.24)\end{array}$ & $\begin{array}{c}0.36 \\
(0.13- \\
0.81)\end{array}$ & $\begin{array}{l}2.28(0.29- \\
7.30)\end{array}$ \\
\hline & $\begin{array}{c}0.71[0.46, \\
1.31]\end{array}$ & $\begin{array}{c}26.7[16.3, \\
34.7]\end{array}$ & $5.24[3.21,7.28]$ & $1.76[0.66,4.69]$ & $4.74[2.75,6.55]$ & $\begin{array}{c}0.24 \\
{[0.16} \\
0.53]\end{array}$ & $\begin{array}{r}0.28 \\
{[0.20} \\
0.52]\end{array}$ & $\begin{array}{l}1.49[0.85, \\
3.18]\end{array}$ \\
\hline \multirow[t]{2}{*}{$\begin{array}{l}\mathrm{e} \\
\mathrm{de} \\
\mathrm{r})\end{array}$} & $\begin{array}{c}0.40(0.09- \\
1.26)\end{array}$ & $\begin{array}{l}0.42(0.06- \\
0.99)\end{array}$ & $\begin{array}{l}0.80(0.17- \\
2.07)\end{array}$ & $\begin{array}{l}0.31(0.15- \\
0.76)\end{array}$ & $0.79(0.07-2.59)$ & $\begin{array}{l}0.69 \\
(0.12- \\
3.11)\end{array}$ & $\begin{array}{c}0.59 \\
(0.24- \\
1.07)\end{array}$ & $\begin{array}{l}0.73(0.12- \\
2.51)\end{array}$ \\
\hline & $\begin{array}{c}0.33[0.23, \\
0.48]\end{array}$ & $\begin{array}{c}0.410 .25 \\
0.54]\end{array}$ & $0.72[0.59,1.00]$ & $0.28[0.20,0.38]$ & $0.71[0.49,1.01]$ & $\begin{array}{rr}f & \\
& 0.41 \\
& 0.31 \\
& 0.68] \\
\end{array}$ & $\begin{array}{r}0.58 \\
{[0.43} \\
0.72]\end{array}$ & $\begin{array}{c}0.66[0.32 \\
0.95]\end{array}$ \\
\hline \multirow[t]{2}{*}{$\begin{array}{l}\text { se } \\
\text { ne) }\end{array}$} & $\begin{array}{l}\text { 08:26 (00:06- } \\
23: 18)\end{array}$ & $\begin{array}{l}\text { 13:06 (01:30- } \\
23: 42)\end{array}$ & $\begin{array}{l}\text { 13:00 (00:06- } \\
23: 42)\end{array}$ & $\begin{array}{c}\text { 10:08 (00:.01- } \\
23: 36)\end{array}$ & $\begin{array}{c}\text { 11:13 (00:00- } \\
23: 30)\end{array}$ & $\begin{array}{l}10: 44 \\
(00: 24- \\
23: 36)\end{array}$ & $\begin{array}{l}11: 39 \\
(00: 06- \\
23: 48)\end{array}$ & $\begin{array}{c}13: 30(00: 06- \\
23: 54)\end{array}$ \\
\hline & $\begin{array}{c}06: 42[02: 36 \\
12: 24]\end{array}$ & $\begin{array}{c}12: 54 \text { [09:06 } \\
19: 00]\end{array}$ & $\begin{array}{c}12: 00[7: 42 \\
19: 18]\end{array}$ & $\begin{array}{c}9: 48[04: 18 \\
14: 42]\end{array}$ & $\begin{array}{c}10: 24[05: 88, \\
19: 01]\end{array}$ & $\begin{array}{r}10: 27 \\
{[05: 42} \\
12: 48]\end{array}$ & $\begin{array}{r}12: 27 \\
{[05: 20} \\
17: 50] \\
\end{array}$ & $\begin{array}{c}\text { 13:06 [06:45, } \\
20: 48]\end{array}$ \\
\hline
\end{tabular}

Results from cosinor analyses of nucleosides urinary excretion in St 3. Parameters are summarised by their mean values, (ranges), median values and $\left[1^{\text {st }}, 3^{\text {rd }}\right]$ quartiles using imputed values from each individual patient, irrespective of statistical validation of a rhythm. Table 3

\section{Figures}




\begin{tabular}{|c|c|c|}
\hline & \multicolumn{2}{|l|}{39 MCC patients* } \\
\hline$\sqrt{ }$ & $\downarrow$ & $\downarrow$ \\
\hline $\begin{array}{c}\text { Study } 1 \\
\text { Liver mets resection } \\
N=10 \text { patients }\end{array}$ & $\begin{array}{c}\text { Study } 2 \\
\text { Chronochemotherapy } \\
N=16 \text { patients* }\end{array}$ & $\begin{array}{c}\text { Study } 3 \\
\text { Circadian patterns } \\
N=30 \text { patients* }\end{array}$ \\
\hline & $\dot{i}$ & $\dot{\vdots}$ \\
\hline$\vdots$ & $\begin{array}{l}\text { Wrist actimetry } \\
\text { (3 days before, } 14 \text { days } \\
\text { after course onset) } \\
N=16 \text { patients }\end{array}$ & $\begin{array}{l}\text { Wrist actimetry } \\
\text { (days } 1 \text { to } 5 \text { ) } \\
N=28 \text { patients }\end{array}$ \\
\hline$\vdots$ & $\underline{\vdots}$ & Eight nucleosides \\
\hline $\begin{array}{c}\text { Six nucleosides } \\
\text { in first morning void } \\
\text { (3 days before, } 7 \text { days } \\
\text { after surgery) } \\
N=10 \text { patients }\end{array}$ & $\begin{array}{l}\text { Six nucleosides } \\
\text { in first morning void } \\
\text { (3 days before, } 14 \text { days } \\
\text { after course onset) } \\
N=14 \text { patients }\end{array}$ & $\begin{array}{c}\text { in fractionated urines } \\
\text { at } 7: 00,11: 00,15: 00 \\
19: 00,23: 00 \text { over } 48 \mathrm{~h} \\
\text { (days } 4 \text { to } 5 \text { ) } \\
N=29 \text { patients }\end{array}$ \\
\hline
\end{tabular}

Figure 1

Consort diagram of three studies in patients with metastatic colorectal cancer (MCC). Twelve patients participated in Studies 2 and 3, three patients participated in Studies 1 and 3, and one patient participated in the three studies.
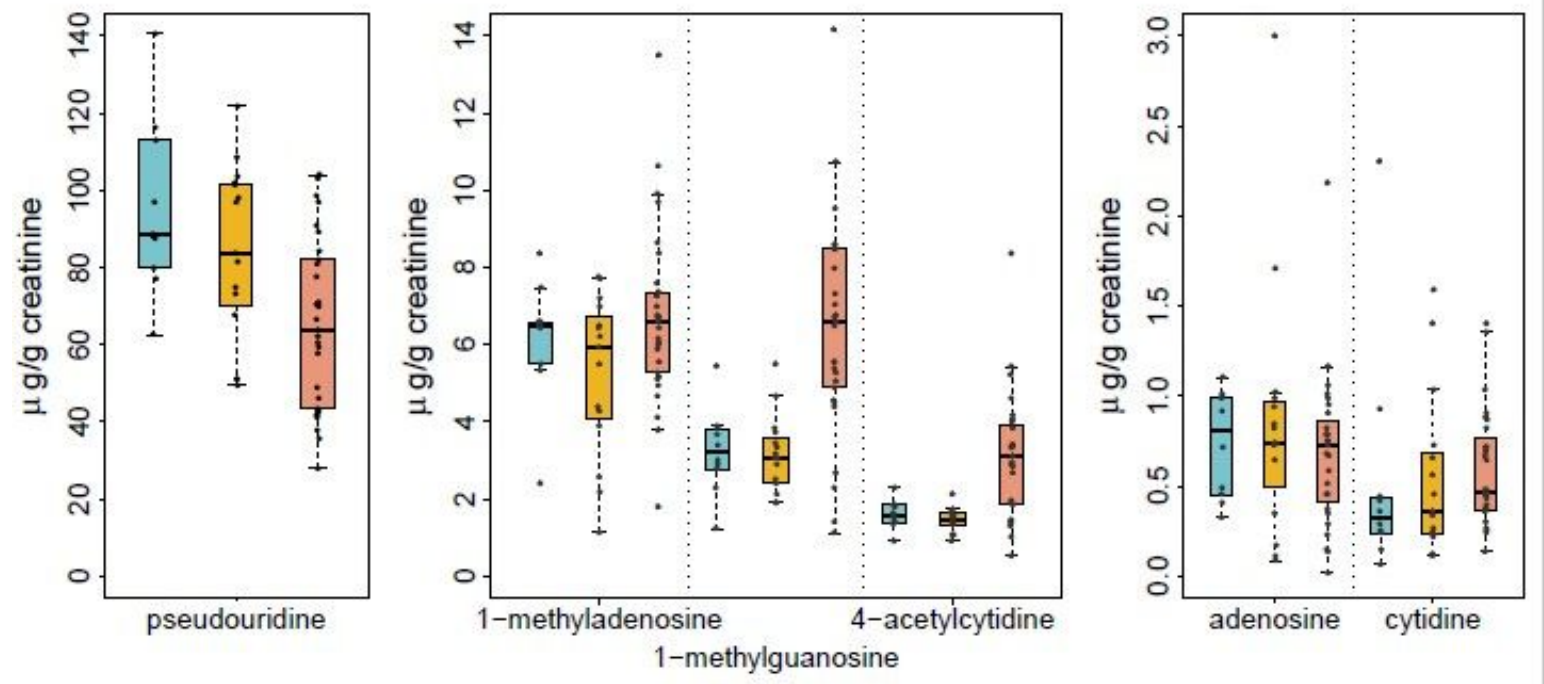

Figure 2

Distribution of early morning urinary excretion values of the 6 modified nucleosides at baseline in the three studies. Nucleosides excretions are ranked from highest (pseudouridine) to lowest (cytidine). Median values, interquartile and extreme values are shown as boxplots for each nucleoside in each study. Note, slight differences in median values and/or range of pseudouridine, 1methylguanosine and 4-acetylcytidine excretions between patients in St3 and patients in St1 or 2. 


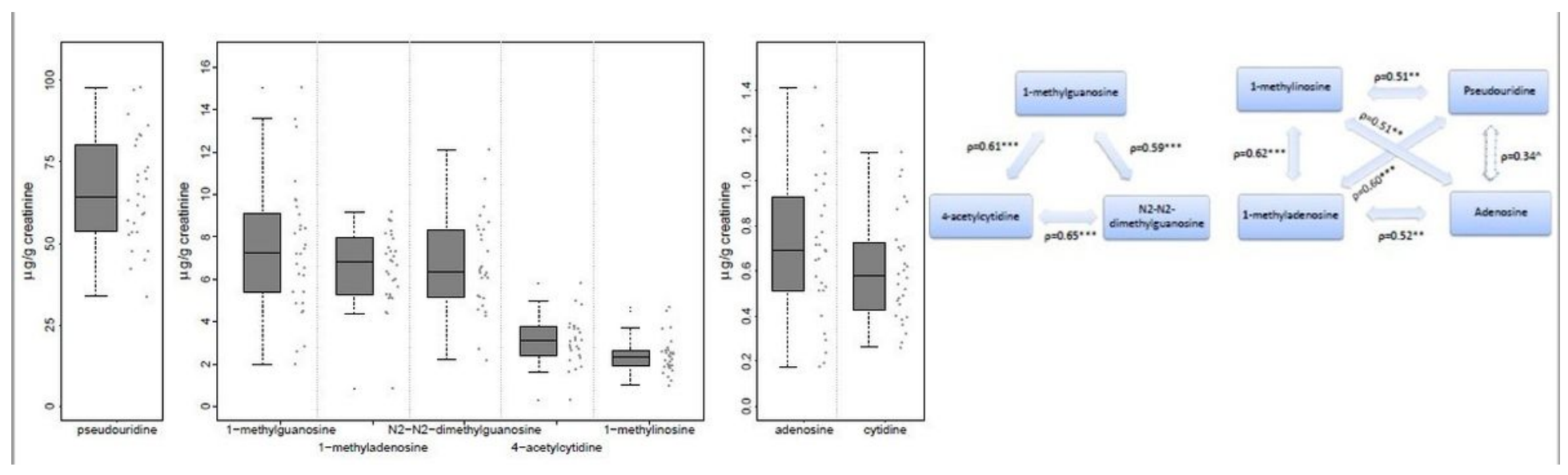

Figure 3

Distribution of urinary excretion mesor values for the 8 modified nucleosides and their intercorrelations in St 3. (1) Mesor estimates with the boxplots (median, interquartile and extreme values) for each nucleoside, ranked from highest to lowest median excretion values. (2) Diagram of intercorrelations. Spearman's rank correlation coefficients $\rho$ with stars indicating $p$-value

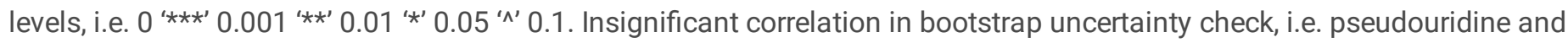
adenosine, is marked with dashed line.

Patient A
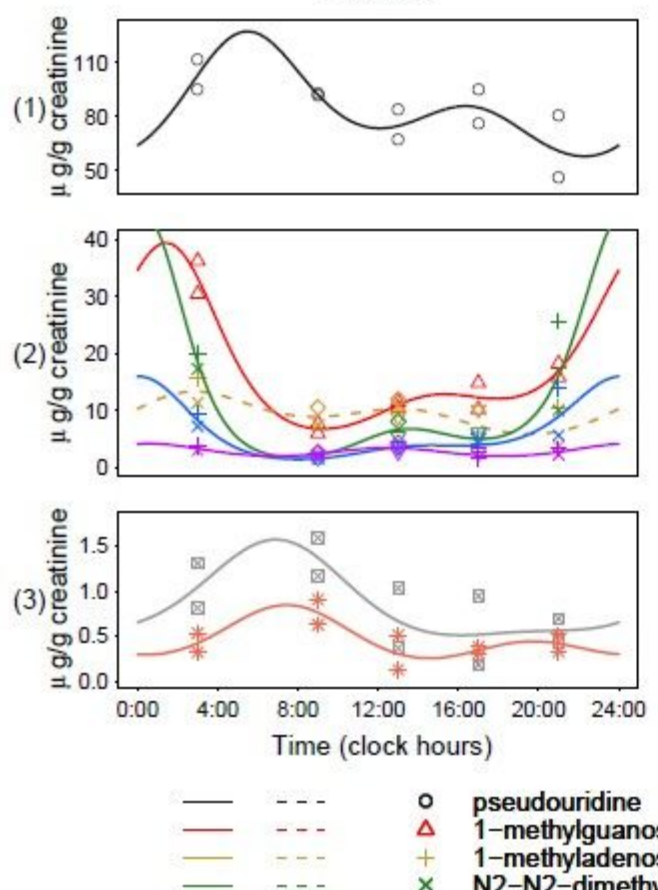

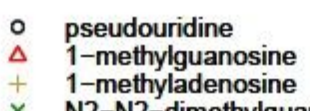

$\times \quad$ N2-N2-dimethylguanosine
Patient B
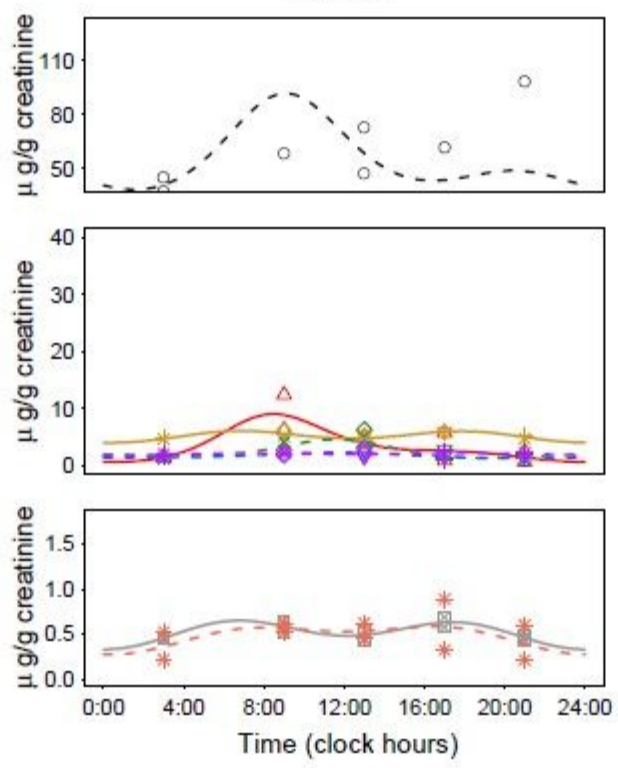

Patient C
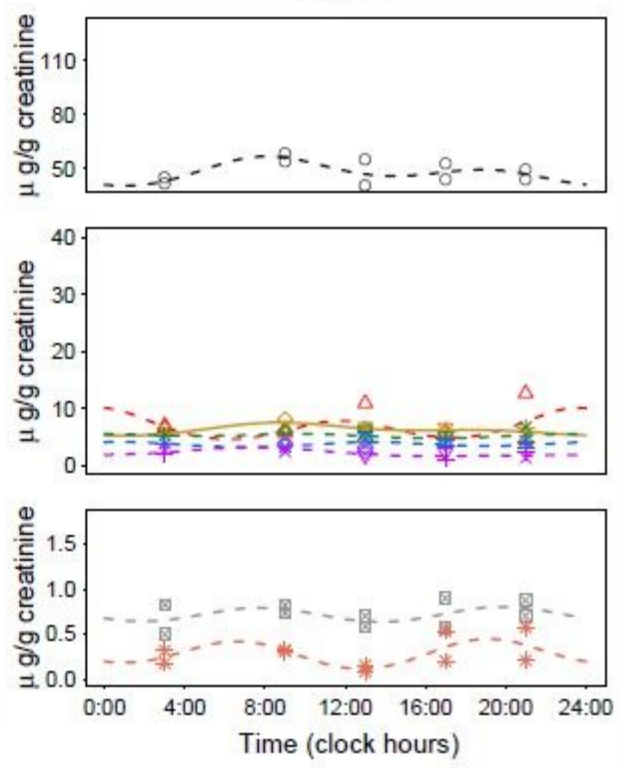

$\begin{array}{llll}- & - & \diamond & \text { 4-acetylcytidine } \\ - & -- & \nabla & 1-\text { methylinosine } \\ -\cdots & \text { adenosine } \\ -\cdots & * & \text { cytidine }\end{array}$

\section{Figure 4}

Interpatient differences in 24-h excretion patterns of urinary nucleosides in St 3. Urinary nucleoside excretion measurements (dots) and multiple-component cosinor model fitting (lines) for example patients A, B and C. Nucleosides identified with significant circadian rhythmic pattern are plotted in solid line while insignificant rhythmic ones are in dashed line. Nucleosides in similar scales are displayed in one panel. 

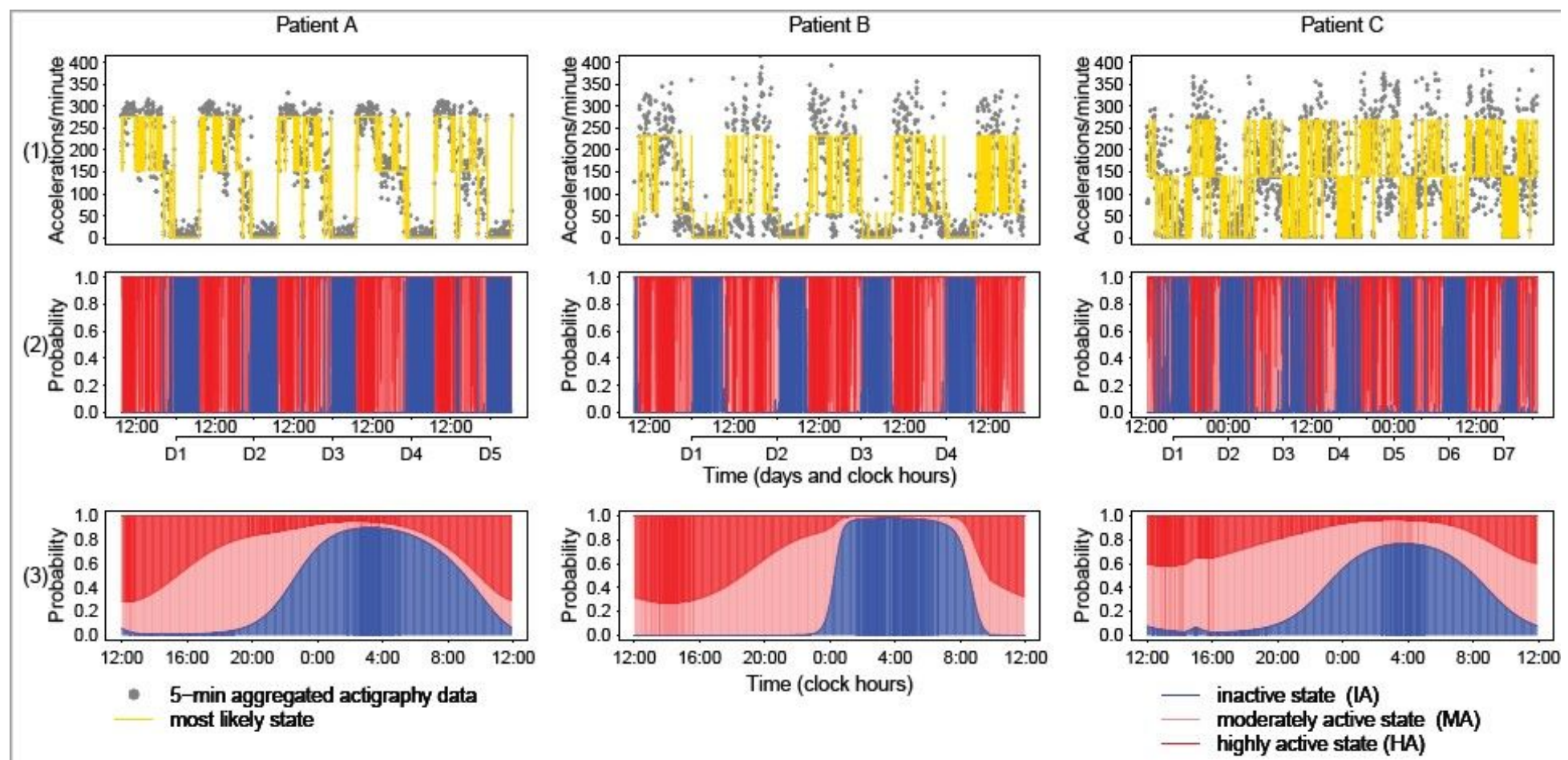

Figure 5

Interpatient differences in 24-h patterns in rest-activity. Profiles of the same three St 3 patients selected for Figure 4. (1) Plotted time series of wrist watch activity measurements. Time series of activity in dots, and corresponding HMM-decoded most likely states connected with a yellow line (lowest level for IA -inactive, middle level for MA - moderately active, and highest level for HAhighly active). (2) Corresponding most likely states, i.e. IA, MA or HA, with frequent state transitions between MA and HA during daytime. Cumulative state probability plots for IA (blue), MA (light red) and HA (dark red) states. (3) Temporal distribution of the three state probabilities over the 24 hours, providing a fingerprint of the individual's typical daily rest-activity behaviour. Patients $A$ and $B$ had solid blue areas $(I A)$ at night while patient $C$ had many interruptions. This was translated into low values for $p 1-1$ and $1<0$. A sharp incline/decline of the blue IA profile is indicative of regular times for retiring in the evening and awakening in the morning. The prolonged IA period of Patient B started around 0:00-1:00 am and ended around 8:00-9:00 am every day with no noticeable interruptions to the IA state in-between, hence this patient has the highest Rhythm Index among the three patients shown. Values of rest-activity indices: patient A: $1<0: 99.7 \%$, Rhythm Index $=67.3 \%, p 1-1=0.969$, r24 = 0.654; patient B: $\mid<0$ : 98.2\%, Rhythm Index $=91.2 \%$, p1-1 $=0.972$, r24 = 0.392; patient C: $1<0: 90.6 \%$, Rhythm Index = 54.6\%, p1-1 = 0.910, r24 =0.247. 


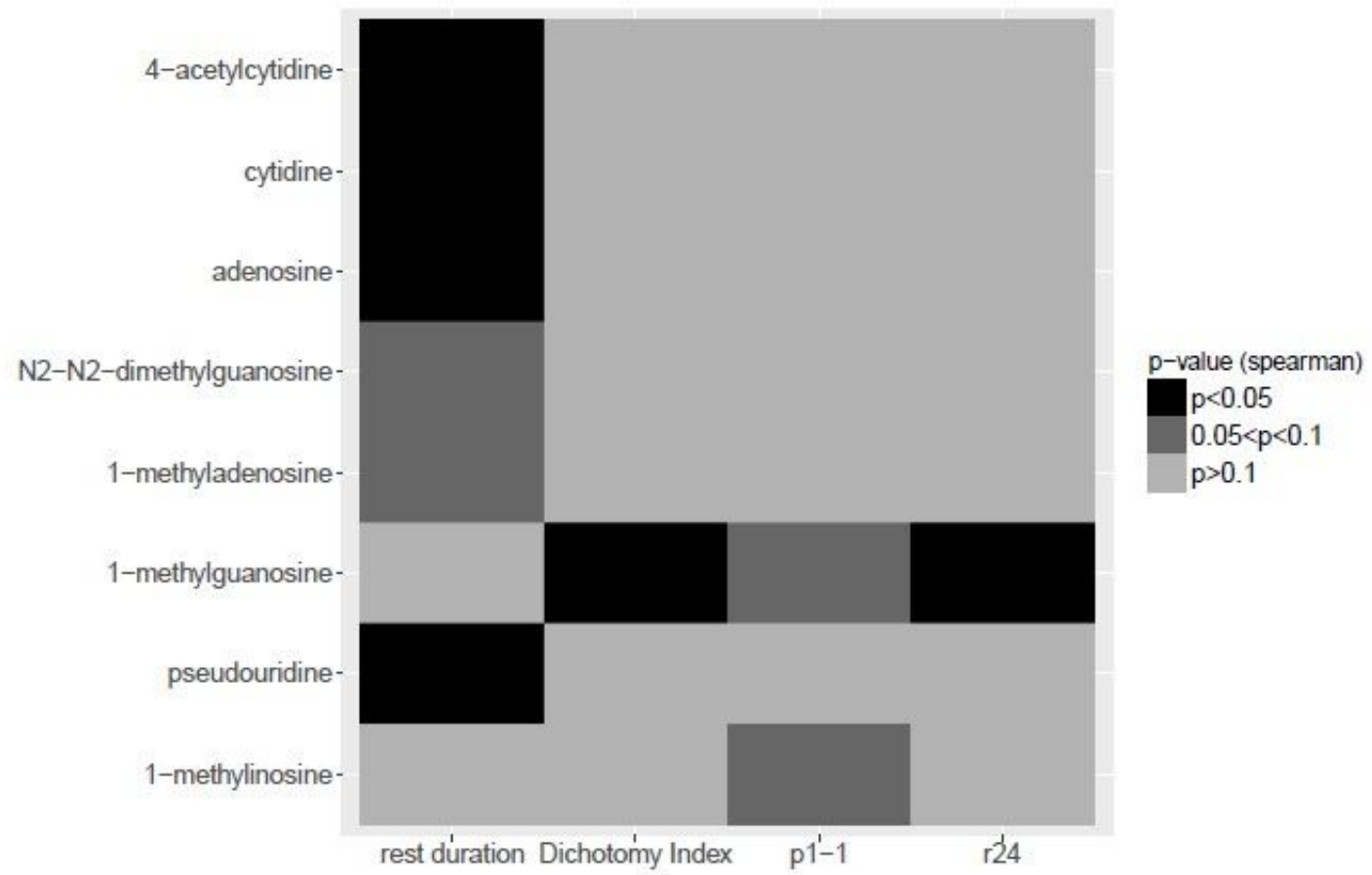

\section{Figure 6}

Grid plots of intercorrelations between selected rest-activity indices and urinary nucleoside excretion relative amplitudes in St 3 . Significance levels are marked in black (Spearman's correlation $p$-value $\leq 0.05)$, dark grey $(0.05<p \leq 0.1)$. Insignificant correlations are in light grey $(p>$

\section{Supplementary Files}

This is a list of supplementary files associated with this preprint. Click to download.

- FigureS1.pdf

- FigureS3study12pts1methylguanosine.pdf

- FigureS5study3HMMcorrelation.pdf

- FigureS2Rldiagram.pdf

- TableS1study3distributionofrestactivityparameters.docx

- FigureS4study23ptscytidine.pdf 